Supporting Information:

\title{
In-situ Raman Spectroscopy of Sulfur Speciation in
}

\section{Lithium-Sulfur Batteries}

\author{
Heng-Liang Wu, Laura A. Huff, Andrew A. Gewirth*
}

Department of Chemistry, University of Illinois at Urbana-Champaign, $600 \mathrm{~S}$.

Mathews Avenue, Urbana, IL 61801 USA

*Corresponding Author. Email: agewirth@illinois.edu. Telephone: 217-333-8329.

Fax: 217-244-5186.

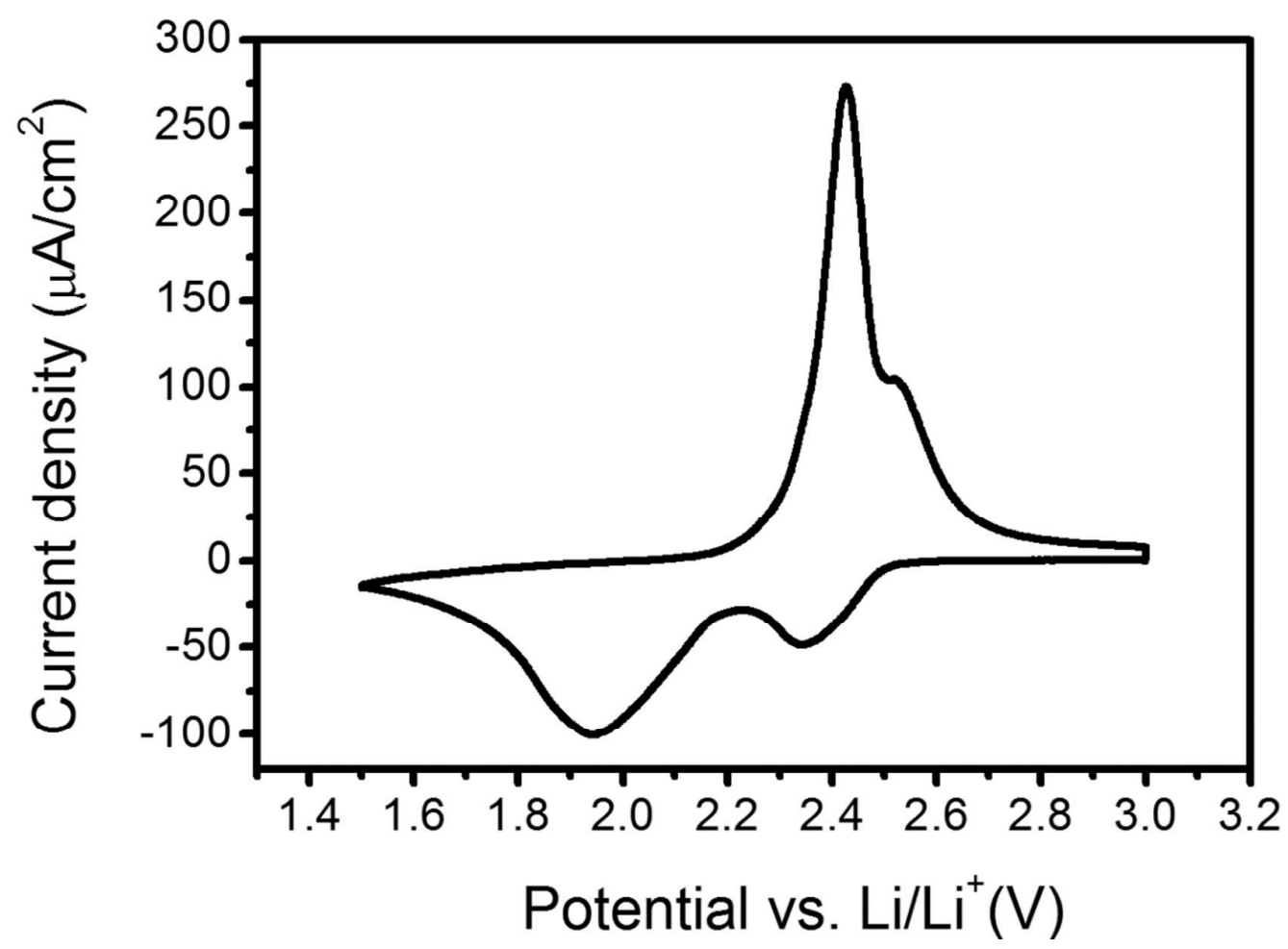

Figure S1. Cyclic voltammetry of the as-prepared sulfur-carbon cathode at a scan rate of $20 \mu \mathrm{V} / \mathrm{s}$ in a coin cell. 


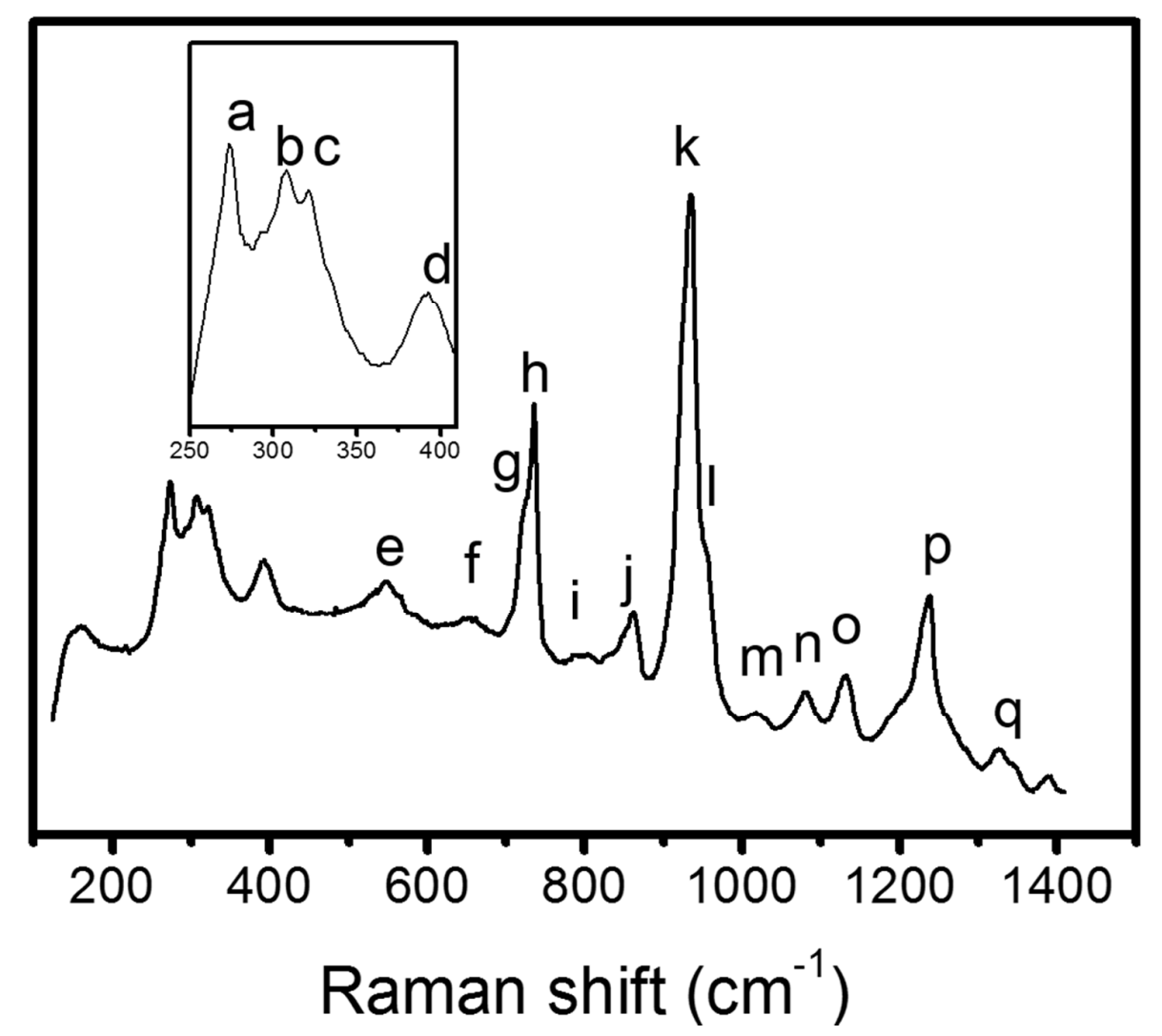

Figure S2. In-situ Raman spectra of the sulfur-carbon cathode shown at $3.2 \mathrm{~V}$ in $1 \mathrm{M}$ LiTFSI with TEGDME/DIOX (1:1, by vol).

\begin{tabular}{|c|c|c|}
\hline Peak label & Peak position $\left(\mathrm{cm}^{-1}\right)$ & Assignment $\left(\mathrm{cm}^{-1}\right)$ \\
\hline a & 273 & $\mathrm{CF}_{3}$ (rocking mode from $\mathrm{TFSI}$ ) \\
\hline $\mathrm{b}$ & 307 & $\mathrm{SO}_{2}$ (rocking made from TFSl-) \\
\hline c & 321 & $\mathrm{SO}_{2}$ (rocking mode from TFSI) \\
\hline$d$ & 392 & $\mathrm{SO}_{2}$ (wagging mode from TFSI) \\
\hline e & $522-573$ (broad peak) & $\begin{array}{l}\mathrm{O}-\mathrm{C}-\mathrm{C} \text { (bending mode form TEGDME) } \\
\mathrm{CF}_{3} \text { (bending mode from TFSI) }\end{array}$ \\
\hline$f$ & 644-661 (broad peak) & $\begin{array}{l}\text { SNS (bending mode from TFSI-) } \\
\text { Ring deformation from 1,3-Dioxolane }\end{array}$ \\
\hline $\mathrm{g}$ & 722 & C-O-C (bending mode from 1,3-Dioxolane) \\
\hline $\mathrm{h}$ & 735 & $\mathrm{CF}_{3}$ (bending mode from TFSI) \\
\hline $\mathrm{i}$ & $782-810$ (broad peak) & C-S (stretching mode from TFSI) \\
\hline j & 863 & $\mathrm{CH}_{2}$ (rocking mode from TEGDME) \\
\hline $\mathrm{k}$ & 934 & C-O + C-C (stretching mode from 1,3-Dioxolane) \\
\hline 1 & 955 & C-O (stretching mode from 1,3-Dioxolane) \\
\hline $\mathrm{m}$ & 1023 & C-O stretching from TEGDME \\
\hline $\mathrm{n}$ & 1080 & $\mathrm{C}$-O stretching and $\mathrm{CH}_{2}$ rocking mode from 1,3-Dioxolane \\
\hline o & 1132 & $\mathrm{SO}_{2}$ (stretching mode from TFSI) \\
\hline$p$ & 1237 & $\mathrm{CH}_{2}$ (twisting mode from 1,3-Dioxolane) \\
\hline$q$ & 1325 & $\mathrm{CH}_{2}$ (wagging mode from 1,3-Dioxolane) \\
\hline
\end{tabular}

Table S1. Vibrational frequencies and assignments for TFSI', TEGDME and DIOX as shown in Figure S2. ${ }^{1-4}$ 

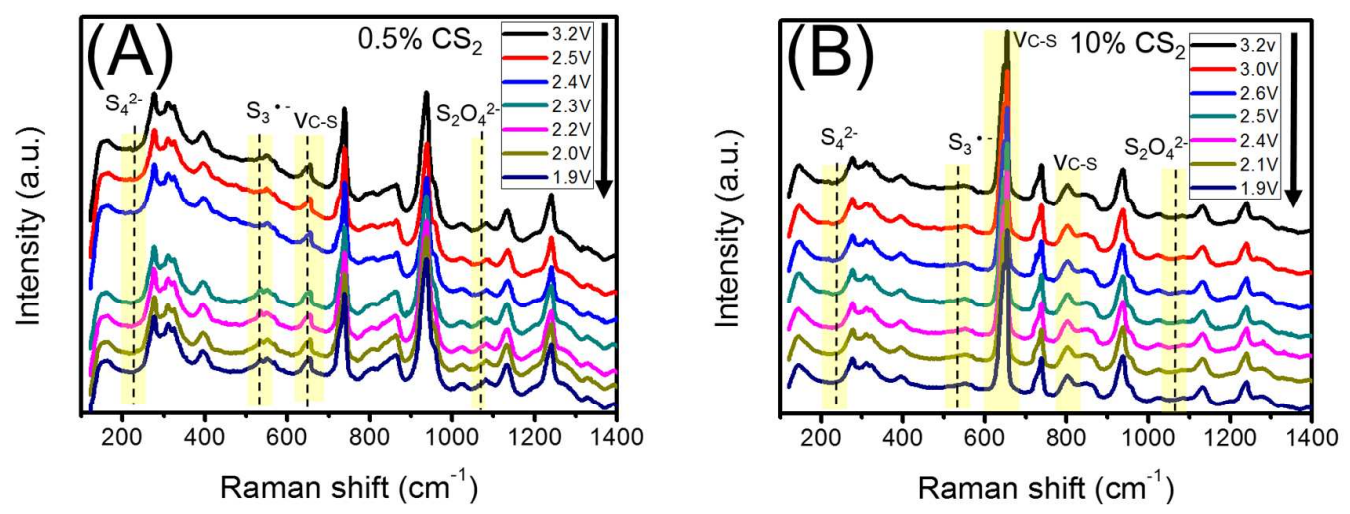

Figure S3. In-situ Raman spectra of sulfur-carbon cathode obtained during discharge with (A) $0.5 \% \mathrm{CS}_{2}$ additive and (B) $10 \% \mathrm{CS}_{2}$ additive (by vol.) at $3.2 \mathrm{~V}^{5,6}$

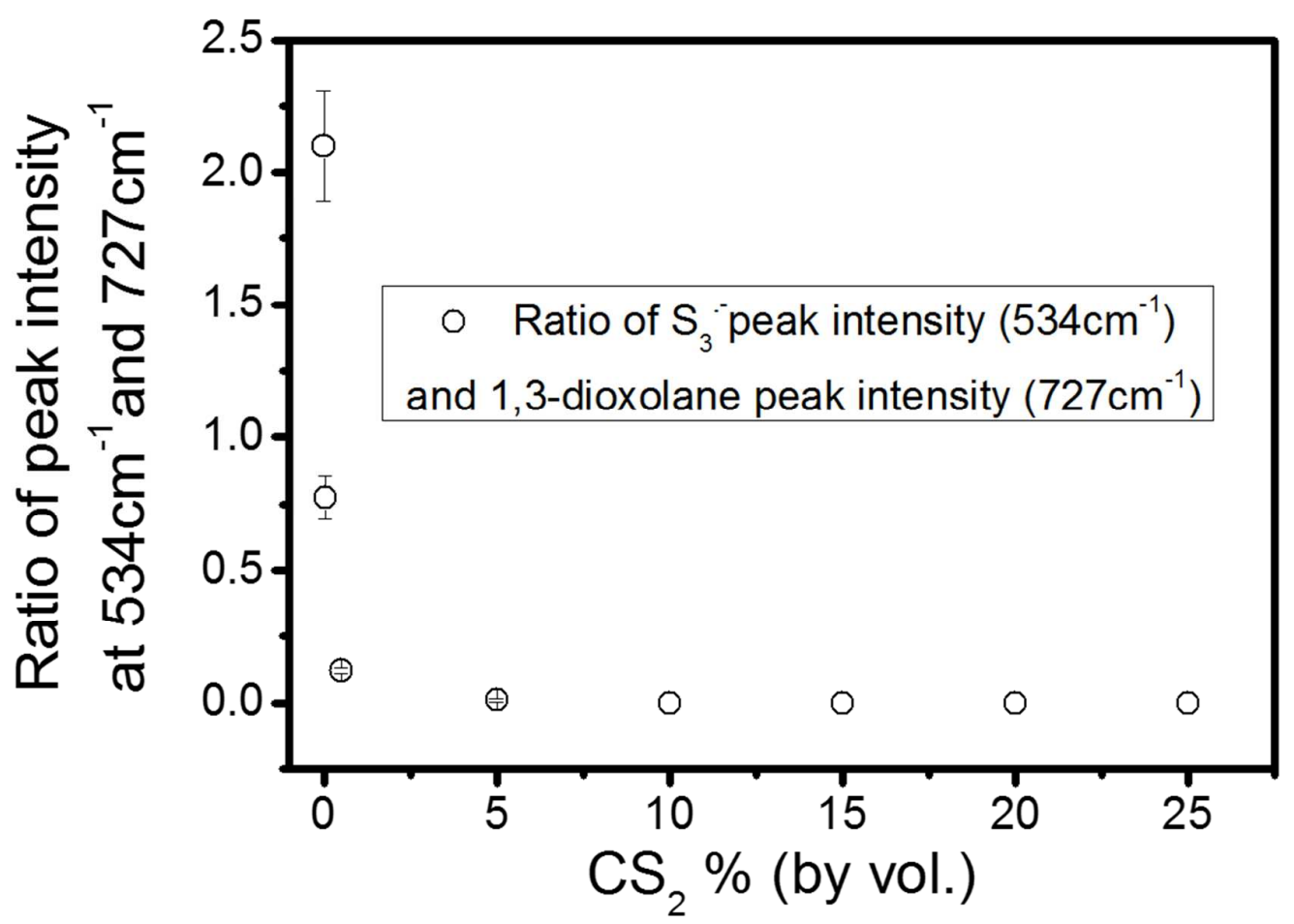

Figure S4. The ratio of maximum peak intensity for $\mathrm{S}_{3}{ }^{\cdot-}\left(534 \mathrm{~cm}^{-1}\right)$ and C-O-C bending mode of 1,3-dioxolane $\left(727 \mathrm{~cm}^{-1}\right)$ were plotted as a function of different amounts of $\mathrm{CS}_{2}$.

Figure $\mathrm{S} 4$ shows the peak intensity ratio of the $\mathrm{S}_{3}{ }^{--}$peak at $534 \mathrm{~cm}^{-1}$ and the $\mathrm{C}$-O-C bending mode of 1,3-dioxolane at $727 \mathrm{~cm}^{-1}$ as a function of different amounts of added $\mathrm{CS}_{2}$. The intensity of the 1,3-dioxolane peak at $727 \mathrm{~cm}^{-1}$ is constant and can 
be used as an internal standard. This result shows the formation of $\mathrm{S}_{3}{ }^{-}$in the second anodic peak is suppressed with $\mathrm{CS}_{2}$ addition. The ratio quickly drops with addition of as little as $0.05 \% \mathrm{CS}_{2}$ and $\mathrm{S}_{3}{ }^{\cdot-}$ formation was not observed with $10 \%$ or more $\mathrm{CS}_{2}$.

\section{References:}

(1) de Zea Bermudez, V.; Lucazeau, G.; Abello, L.; Poinsignon, C. Infrared and Raman spectroscopic study of polyether solutions of sulphamide Part I:

Tetraethyleneglycol dimethyl ether and water. J. Mol. Struct. 1993, 301, 7-19.

(2) Mohaček-Grošev, V.; Furić, K.; Ivanković, H. Observed bands in Raman and infrared spectra of 1,3-dioxolane and their assignments. Vib. Spectrosc. 2013, 64, 101-107.

(3) Rey, I.; Johansson, P.; Lindgren, J.; Lassègues, J. C.; Grondin, J.; Servant, L. Spectroscopic and Theoretical Study of (CF3SO2)2N- (TFSI-) and (CF3SO2)2NH (HTFSI). J. Phys. Chem. A 1998, 102, 3249-3258.

(4) Castriota, M.; Caruso, T.; Agostino, R. G.; Cazzanelli, E.; Henderson, W. A.; Passerini, S. Raman Investigation of the Ionic Liquid N-Methyl-N-propylpyrrolidinium Bis(trifluoromethanesulfonyl)imide and Its Mixture with LiN(SO2CF3)2. J. Phys. Chem. A 2004, 109, 92-96.

(5) Langseth, A.; So/rensen, J. U.; Nielsen, J. R. Raman Spectrum of Carbon Disulphide. J. Chem. Phys. 1934, 2, 402-409.

(6) Ito, M. Raman and Infrared Spectra of Crystalline Carbon Disulfide. $J$. Chem. Phys. 1965, 42, 815-818. 